\title{
Mastication and oral motor function in McArdle disease: patient reported complaints
}

\author{
CV Kouwenberg ${ }^{1}$, NC Voermans ${ }^{1}$, R Quinlivan ${ }^{2}$, L van den Engel-Hoek ${ }^{3}$ \\ ${ }^{1}$ Department of Neurology, Donders Institute for Brain, Cognition, and Behaviour, Radboud \\ University Medical Centre, Nijmegen, the Netherlands \\ ${ }^{2}$ MRC Centre for Neuromuscular Diseases and Department of Molecular Neuroscience, University \\ College London Institute of Neurology and National Hospital for Neurology and Neurosurgery, Queen \\ Square, London WC1N 3BG, UK \\ ${ }^{3}$ Department of Rehabilitation, Donders Centre for Neuroscience, Radboud University Medical \\ Centre, Nijmegen, the Netherlands
}

Corresponding author:

Dr. N.C. Voermans

Neurologist

Radboud University Medical Centre

Department of Neurology

P.O. Box 9101

6500 HB Nijmegen

The Netherland

Phone: 0031243615187

Email address: Nicol.Voermans@radboudumc.nl

Number of references: 10

Number of tables: 2

Number of figures: 0

Word count abstract: 186

Word count paper (excluding abstract, acknowledgments, references and figure legends): 1516 


\section{Abstract}

BACKGROUND: Exertional myalgia and cramps of the limb and trunk muscles are typical in McArdle disease, but mastication and oral motor limitations have not been systematically investigated before. OBJECTIVE: Determine the reported prevalence and characteristics of limitations on oral motor activities, mastication, swallowing, and other oral motor activities in patients with McArdle disease.

METHODS: An observational study was carried out in 28 patients using a standardised questionnaire on mastication and oral motor function.

RESULTS: $57 \%$ of the participants reported difficulties with mastication. Muscle cramps during mastication occurred in $57 \%$ of the patients. Dysphagia including a feeling that food remains in the throat occurred in $32 \%$. Adaptations during mastication were needed in $42 \%$ of the patients. Mastication difficulties, muscle cramps during mastication and mastication adjustments were inversely correlated with age $\left(r_{2}=-0.445, p<0.05 ; r_{2}=-0.509, p<0.01 ; r_{2}=-0.456, p<0.05\right)$. Dysphagia, cramps during mastication and during other oral motor muscle activities, were correlated with disease severity $\left(r_{2}=0.476, p<0.01 ; r_{2}=0.463, p<0.01 ; r_{2}=0.461, p<0.01 ; r_{2}=0.432, p<0.05\right)$.

CONCLUSIONS: In short, reported mastication difficulties are prevalent in people with McArdle disease, most frequently in younger people. Therefore, awareness of mastication and oral motor problems is required.

Keywords: McArdle disease, glycogen storage disease type $\mathrm{V}$, mastication, oral motor function. 


\section{Introduction}

McArdle disease (glycogen storage disease type $\mathrm{V}$ ) is a rare autosomal recessive disorder of glycogen metabolism affecting exclusively striated muscle. Most affected individuals have no detectable muscle glycogen phosphorylase, as a consequence affected people cannot utilize stored muscle glycogen as an energy source. This leads to exercise-induced myalgia, muscle stiffness, fatigue and mild limb-girdle weakness in some patients over 40 years of age. When exercise is continued, painful muscle camps occur, contracture and eventually rhabdomyolysis [1]. Another typical sign is the second wind phenomenon, which occurs due to a switch to extra-muscular fuel substrates required for aerobic metabolism with increased muscle blood flow $[2,3]$.

Since chewing and swallowing involves repetitive, sometimes powerful activity of the bulbar muscles, McArdle disease is expected to be associated with symptoms of oral motor activities. However, reports on oral motor dysfunction is limited to two case reports describing tenderness and myalgia of the masticatory muscles while chewing $[4,5]$. We performed an observational study $(1)$ to determine the prevalence and characteristics of patient-reported oral motor limitations (mastication, swallowing and other) in people with McArdle disease; (2) to determine the correlation between oral motor limitations and age and disease severity.

\section{Materials and Methods}

\section{Participants}

Participants were identified from the database of the Radboud university medical centre. We invited all 35 known patients with McArdle disease in our neuromuscular expertise centre on neuromuscular disorders. In this questionnaire-based study, 28 people with McArdle disease took part (10 males and 18 females), ranging ages between 18 and 83 years. The diagnosis of McArdle disease was confirmed by DNA analysis of PYGM in 25 of the participants and by muscle biopsy (demonstrating an absence 
of muscle glycogen phosphorylase and accumulation of glycogen) and non-ischemic forearm test (ammonia rise without lactate rise) in two participants. In one person DNA analysis was not performed, because a sibling with the same symptoms showed compound heterozygous mutations in PYGM confirming McArdle disease. All participants were also registered in the EUROMAC registry [6].

\section{$\underline{\text { Questionnaire }}$}

All participants received and returned a semi-quantitative questionnaire by mail or email. The questionnaire involved 11 questions concerning oral motor activities (mastication, swallowing and other) [7]. Disease severity was determined from the patients' medical records and was measured on a scale from 0 to 3, with 0: asymptomatic or virtually asymptomatic (mild exercise intolerance but no functional limitation in any daily life activity). 1: exercise intolerance camps, myalgia and limitation of acute and strenuous exercise and occasionally in daily life activities; no record of myoglobinuria, no muscle wasting or weakness. 2: same as 1 plus recurrent exertional myoglobinuria, moderate restriction in exercise and limitation in daily life activities. 3: same as 2 plus fixed muscle weakness with or without wasting and severe limitation on exercise and most daily activities [6]. This severity scale was validated for McArdle disease and other rare glycogenolytic disorders.

\section{$\underline{\text { Statistical analysis }}$}

Descriptive statistics were used to determine the general characteristics of the participants, and the prevalence of the reported complaints concerning mastication, swallowing and other oral motor activities. The Spearman correlation coefficient was used to determine the relation between age and disease severity, and symptoms associated with mastication and dysphagia. Results with two-tailed $p$-values $<0.05$ were considered significant. Statistical analyses were carried out using SPSS 22.0 for Windows (IBM Corp., Armonk, NY, USA). 


\section{Results}

A total of 28 people with McArdle disease participated in this study, of which $29 \%(n=8)$ had a disease severity score of $1 ; 57 \%$ had a disease severity score of 2; and $14 \%$ a score of 3 (Table 1 ). None were asymptomatic. Of the participants, 57\% reported difficulties with mastication. Thirteen participants (46\%) reported the need for adaptations during mastication that involved chopping the food or avoiding chewy meat. Three participants (11\%) reported to eat very slowly, one of whom needed more than 30 minutes to complete his meal. Muscle camps during mastication occurred in $57 \%$ of the participants, one of them reported 'very frequent' camps (multiple times a day). Camps in muscles of the jaw, tongue or lips during other oral motor activities were reported less often $(46 \%, n$ = 13). These activities included blowing, laughing, talking, sucking or playing a wind instrument. Most camps took place during blowing $(11 \%)$ or laughing $(11 \%)$. Two participants reported more camps in the evening, and one had more camps in the morning. Dysphagia in terms of the inability to swallow occurred 'rarely' (less than once daily) in only three of the participants (11\%). Almost one third of the participants $(32 \%, n=9)$ reported that they sometimes experienced a feeling of food sticking in their throat.

Mastication problems $\left(r_{2}=-0.445, p<0.05\right)$, camps during mastication $\left(r_{2}=-0.509, p<0.01\right)$, and mastication adjustments $\left(r_{2}=-0.456, p<0.05\right)$ were significantly inversely correlated to age (Table 2$)$. The correlation between age and other characteristics was not statistically significant. Three characteristics were significantly correlated with disease severity with $p<0.01$, namely feeling of food sticking in the throat $\left(r_{2}=0.476\right)$, camps during mastication $\left(r_{2}=0.463\right)$, and camps of the jaws, tongue or lips during other oral motor activities $\left(r_{2}=0.461\right)$. The correlation between disease severity, and camps in muscles of the jaw, tongue or lips during other oral motor activities (blowing, laughing, talking, sucking or playing a wind instrument) was $0.432, p<0.05$. The prevalence of mastication problems was correlated with mastication adjustment (yes $/ \mathrm{no})\left(r_{2}=0.546, p=0.003\right)$. 


\section{Discussion}

This questionnaire-based study in 28 people with McArdle disease showed that mastication limitations are frequently reported (57\%). Mastication difficulties were reported more frequently in younger people, while in most other neuromuscular disorders limitations increase during age. Most likely, people with McArdle disease learn to cope with these limitations over time. This is in line with Martin et al. (2014) who showed that most affected people can have relatively normal lives, because they learn to adjust their daily activities [8]. In people over age 40 years, fixed skeletal muscle weakness, mostly proximal, was described to be more common, and occurred in about one fourth of the participants [8]. Weakness of masticatory muscles was not investigated; this would be focus of future research. However, we hypothesize that older patients adapt to the masticatory weakness if it occurs and experience no or only mild mastication limitations. We showed that indeed almost $50 \%$ of the participants adapted their solid food intake by cutting it into smaller pieces, by the consumption of softer foods or limited amount of solid foods. This compensation advice is in line with the general recommendations given to prevent limb and trunk muscle cramping in McArdle disease.

Fibre-type composition of the jaw and tongue muscles is very different from that of limb and trunk muscles, which have a combination of type I, lla and IIx myosin heavy chains (MyHC). Jaw muscle fibres are more hybrid, with contractile properties providing fine gradation of movement and force. Glycogen accumulation in McArdle disease occurs in type II fibres, which are also found in the tongue and masseter muscles [9]. Korfage et al (2005) stated that the large variation in fibre types among individuals is influenced by the amount and pattern of activation [9]. Furthermore, a study by Krag et al (2016) showed that relationships between fibre type composition and glycogen metabolism are complicated [10]. We hypothesize that possible differences between fibre type composition of the masseter in McArdle disease and the unclear relationship between fibre type composition and glycogen metabolism might explain differences and wide range of complaints on mastication in our study group. 
The limitation of this study is that it only consists of a semi-quantitative questionnaire. The questionnaire was validated in other diseases [7]. Hence, it was not specifically designed for use in McArdle disease and did not contain any specific questions on second wind phenomenon. Nevertheless, occurrence of a second wind phenomenon in general was reported by $82 \%$ of the participants, and second wind occurring specifically during chewing is frequently encountered in the population in our clinic. This study is the first to investigate experienced mastication and oral motor limitations in people with McArdle disease. The results of the questionnaire were not counterchecked by directly visiting patients and discussing with them about their masticatory (and other) problems. Hence, the logical next step would be to do further research with experimental data and to take notice of masticatory problems in the consulting room.

In short, this questionnaire study shows a prevalence of reported mastication impairment of $57 \%$ in people with McArdle disease. This impairment occurs more frequently in a younger age group. Therefore, awareness of mastication and oral motor limitations is required to adequately advise people with McArdle disease about mastication and oral motor function: avoid peak load during mastication, eat smaller pieces, choose soft food, start slow and take more time to eat. Furthermore, they can be reassured that limitations are not expected to worsen with ageing since most people seem to learn to adequately compensate for this.

\section{Acknowledgements}

We are grateful to the patients who participated to this study.

\section{Conflict of Interest}

The authors have no conflict of interest to report. 
Table 1: Participant characteristics and frequencies of complaints concerning mastication, swallowing and oral motor function

\begin{tabular}{|c|c|}
\hline Participants characteristics & $N(\%)$ \\
\hline Mean age (SE) & $45( \pm 3.3)$ \\
\hline \multicolumn{2}{|l|}{ Sex } \\
\hline Male & $10(35.7 \%)$ \\
\hline Female & $18(64.3 \%)$ \\
\hline \multicolumn{2}{|l|}{ Disease severity* } \\
\hline 0 & 0 \\
\hline 1 & $8(28.6 \%)$ \\
\hline 2 & $16(57.1 \%)$ \\
\hline 3 & $4(14.3 \%)$ \\
\hline \multicolumn{2}{|l|}{ Mastication problems } \\
\hline Never & $12(42.9 \%)$ \\
\hline Rarely & $13(46.4 \%)$ \\
\hline Sometimes & $2(7.1 \%)$ \\
\hline Very often & $1(3.6 \%)$ \\
\hline Always & 0 \\
\hline \multicolumn{2}{|l|}{ Mastication adjustments } \\
\hline Never & $15(53.6 \%)$ \\
\hline Chopping the food & $1(3.6 \%)$ \\
\hline No chewy mead & $6(21.4 \%)$ \\
\hline Limitation of solid food & $1(3.6 \%)$ \\
\hline Only soft or ground food & 0 \\
\hline Other adjustments & $3(10.7 \%)$ \\
\hline Combination of chopping and no chewy mead & $1(3.6 \%)$ \\
\hline $\begin{array}{l}\text { Combination of chopping and other } \\
\text { adjustments }\end{array}$ & $1(3.6 \%)$ \\
\hline \multicolumn{2}{|l|}{ Mealtime duration } \\
\hline Normal & $27(96.3 \%)$ \\
\hline More than 30 minutes & $1(3.6 \%)$ \\
\hline \multicolumn{2}{|l|}{ Feeling of food sticking in throat } \\
\hline Never & 19 (67.9\%) \\
\hline Rarely & $8(28.6 \%)$ \\
\hline Sometimes & $1(3.6 \%)$ \\
\hline Very often & 0 \\
\hline Always & 0 \\
\hline \multicolumn{2}{|l|}{ Muscle cramps during mastication } \\
\hline Never & $12(42.9 \%)$ \\
\hline Rarely & 12 (42.9\%) \\
\hline Sometimes & $3(10.7 \%)$ \\
\hline Very often & $1(3.6 \%)$ \\
\hline Always & 0 \\
\hline \multicolumn{2}{|l|}{ Muscle cramps during other oral motor activities } \\
\hline Never & $15(53.6 \%)$ \\
\hline Rarely & $11(39.3 \%)$ \\
\hline Sometimes & $2(7.1 \%)$ \\
\hline Very often & 0 \\
\hline Always & 0 \\
\hline \multicolumn{2}{|l|}{ Activity during cramps } \\
\hline Never & $18(64.3 \%)$ \\
\hline Blowing & $1(3.6 \%)$ \\
\hline Laughing & $1(3.6 \%)$ \\
\hline Talking & $1(3.6 \%)$ \\
\hline Sucking & $1(3.6 \%)$ \\
\hline Playing wind instrument & $2(7.1 \%)$ \\
\hline Multiple activities & $4(14.3 \%)$ \\
\hline \multicolumn{2}{|l|}{ Influence of time on cramps } \\
\hline Yes & $25(89.3 \%)$ \\
\hline No & $3(10.7 \%)$ \\
\hline \multicolumn{2}{|l|}{ Not able to swallow } \\
\hline Never & 25 (89.3\%) \\
\hline
\end{tabular}




\section{Rarely}

Sometimes

Very often

Always

Influence of time on swallowing

No

Yes

Yes $2(7.1 \%)$

$3(10.7 \%)$

0

0

$26(92.9 \%)$

( daily life activity). 1: exercise intolerance contractures, myalgia and limitation of acute and strenuous exercise and occasionally in daily life activities; No record of myoglobinuria, no muscle wasting or weakness. 2: same as 1 plus recurrent exertional myoglobinuria, moderate restriction in exercise and limitation in daily life activities. 3: same as 2 plus fixed muscle weakness with or without wasting and severe limitation on exercise and most daily activities.

Table 2: Spearman correlation coefficients between age and mastication complaints, swallowing and oral motor activities, and between disease severity and mastication complaints, swallowing and oral motor activities

\begin{tabular}{lll}
\hline $\begin{array}{l}\text { Mastication complaints, swallowing and } \\
\text { oral motor activities }\end{array}$ & Spearman correlation coefficients, $n=28$ & \\
\hline & Correlation with age & Correlation with disease severity \\
Sex & -0.66 & -0.17 \\
Age & - & -0.16 \\
Disease severity & -0.16 & - \\
Mastication problems & $-0.45^{*}$ & 0.35 \\
Mastication adjustments & $-0.46^{*}$ & 0.34 \\
Mealtime duration & -0.30 & 0.05 \\
Feeling of food sticking in throat & 0.18 & $0.48^{* *}$ \\
Muscle cramps during mastication & $-0.51 * *$ & $0.46^{* *}$ \\
Muscle cramps during other oral motor & -0.29 & $0.46^{* *}$ \\
activities & & \\
Activity during cramps & -0.32 & $0.43^{*}$ \\
Influence time on cramps & -0.01 & -0.10 \\
Not able to swallow & -0.17 & 0.26 \\
Influence time on swallowing & -0.22 & 0.27 \\
\hline Significance: $*<0.05 * * p<0.01$ & &
\end{tabular}




\section{References}

[1] Quinlivan R, Vissing J, Hilton-Jones D, Buckley J. Physical training for McArdle disease. Cochrane Database Syst Rev 2011:CD007931. Minor update 2012.

[2] Vissing J, Haller RG. A diagnostic cycle test for McArdle's disease. Ann Neurol 2003;54:53942.

[3] Quinlivan R, Buckley J, James M, Twist A, Ball S, Duno M, et al. McArdle disease: a clinical review. JNNP 2010;81:1182-8.

[4] McArdle B. Myopathy due to a defect in muscle glycogen breakdown. Clin sci 1951;10:13-35.

[5] Thornhill MH. Masticatory muscle symptoms in a patient with McArdle's disease. Oral surgery, oral medicine, oral pathology, oral radiology, and endodontics 1996;81:544-6.

[6] Martinuzzi A, Sartori E, Fanin M, Nascimbeni A, Valente L, Angelini C, et al. Phenotype modulatoris in myophosphorylase deficiency. Ann Neurol 200;53:497-502.

[7] van den Engel-Hoek L, Erasmus CE, van Bruggen HW, de Swart BJ, Sie LT, Steenks MH, et al. Dysphagia in spinal muscular atrophy type II: more than a bulbar problem? Neurology 2009;73:1787-91.

[8] Martin MA, Lucia A, Arenas J, Andreu AL. Glycogen Storage Disease Type V. In: Pagon R A, et al ed. GeneReviews(R). Seattle (WA), 1993.

[9] Korfage JA, Koolstra JH, Langenbach GE, van Eijden TM. Fiber-type composition of the human jaw muscles--(part 2) role of hybrid fibers and factors responsible for inter-individual variation. J Dent Res 2005;84:784-93.

[10] Krag TO, Pinos T, Nielsen TL, Duran J, García-Rocha M, Andreu AL, et al. Differential glucose metabolism in mice and humans affected by McArdle disease 2016;311:R307-14. 